\title{
A invisibilidade da mulher negra na Ciência: uma análise a partir de livros didáticos de Ciência e Biologia
}

\author{
The invisibility of the black woman in Science: an analysis from \\ Science and Biology textbooks
}

La invisibilidad de la mujer negra en la ciencia: un análisis de los libros de texto de Ciencia y biología

Ana Caroline de Oliveira Pereira ${ }^{1}$; Marcelo Alberto Elias²

\section{RESUMO}

A perpetuação do discurso racista e machista na sociedade atual tem influência em todas as áreas e, em especial, na área científica. O presente trabalho objetivou investigar a presença de mulheres negras na história da Ciência, por meio da análise de duas coleções de livros didáticos de Ciência e Biologia. Os livros de Ciências e Biologia analisados foram os do último programa Nacional de livro didático (PNLD), adotados por escolas do município de Cruzeiro do Oeste (PR). Os resultados demonstraram a ausência de relatos sobre a presença de mulheres negras da Ciência. Por fim, com a finalidade de instrumentalização para o ensino na Educação Básica, o presente estudo apresenta uma relação de cientistas negras nas mais diferentes áreas das Ciências Biológicas.

Palavras-chave: Ensino de ciências e biologia; Feminismo; História da ciência; Relações étnico-raciais.

\section{ABSTRACT}

The perpetuation of racist and sexist discourse in current society has influences in all areas and especially in the scientific area. The present work aimed to investigate the presence of black women in the history of science, through the analysis of two collections of science and biology textbooks. The analyzed science and biology books were from the last national textbook plan (PNLD), of the Municipality. from Cruzeiro do Oeste (PR). The results demonstrated the absence of reports on the presence of black women in science. Finally, in order to instrumentalize teaching in basic education, the present study presents a list of black scientists in the most different areas of Biological Sciences.

Keywords: Science and biology teaching; Feminism; History of science; Ethnic-racial relations.

\section{RESUMEN}

La perpetuación del discurso racista y sexista en la sociedad actual tiene influencias en todos los ámbitos y especialmente en el ámbito científico. El presente trabajo tuvo como objetivo investigar la presencia de la mujer negra en la historia de la ciencia, a través del análisis de dos colecciones de libros de texto de ciencia y biología. Los libros de ciencia y biología analizados pertenecen al último Programa Nacional de Libros de Texto (PNLD), adoptado por las escuelas del municipio de Cruzeiro do Oeste (PR). Los resultados demostraron la ausencia de informes sobre la presencia de mujeres negras en la ciencia. Finalmente, con el propósito de instrumentalizar la docencia en la educación básica, el presente estudio presenta un listado de científicos negros en las más diversas áreas de las Ciencias Biológicas.

\footnotetext{
${ }^{1}$ Licencianda em Ciências Biológicas pelo Instituto Federal do Paraná (IFPR), Umuarama, PR - Brasil. E-mail: carolanaolive@gmail.com

${ }^{2}$ Doutorando em Ensino de Ciências e Matemática, Mestre em Biologia das Interações Orgânicas, Especialista em Biotecnologia, Licenciado em Ciências Biológicas e professor EBTT no Instituto Federal do Paraná (IFPR), Umuarama, PR - Brasil. E-mail: marcelo.elias@ifpr.edu.br
} 
Palabras clave: Enseñanza de la ciencia y la biología; Feminismo; Historia de la ciencia; Relaciones étnicoraciales.

\section{INTRODUÇÃO}

A sociedade Brasileira é constituída por uma população com diferentes tonalidades de pele. Segundo levantamentos feitos pelo Instituto de Geografia e Estatística (IBGE, 2019), atualmente o Brasil é formado por aproximadamente 207,8 milhões de habitantes, dentre estes brancos, pardos, amarelos, indígenas e negros. De acordo com a pesquisa realizada em 2018, 43,1\% das pessoas eram de cor brancas, 46,6\% pardos, 0,7\% amarelos, 0,4\% indígenas e 9,3\% negros. Essa diversidade de tons de peles que existente no país estão profundamente enraizadas desde o princípio da sua história, misturas de cores que têm uma forte relação com o "descobrimento do país", em que três povos se encontraram em um mesmo lugar: portugueses, africanos e indígenas.

Segundo Nascimento (2016), assim que os portugueses "descobriram" o Brasil, em 1500, após alguns anos foram trazidos, presos a correntes, milhares de negros para a exploração da nova terra. Estes foram distribuídos inicialmente na região litorânea e, posteriormente, por todo o território, vivendo em condições escravistas, desumanas, sendo tratados como pessoas inferiores.

A importação dos negros para o Brasil foi para utilização da sua força para o trabalho e obtenção de lucro para o império português. A maior parte dos escravos era homens, as mulheres negras existentes eram vistas, pelos portugueses, como objetos de trabalho e sexuais, além de serem completamente proibidas de formar uma estrutura familiar (NASCIMENTO, 2016).

Segundo Cardoso (2018), no período da escravidão acreditava-se que existiam raças, sendo a branca a superior e a negra inferior. Nesta época, portanto, foi implantando em nossa sociedade, processos de padronização de imagem estereotipadas e racistas. Os discursos promovidos no Brasil colônia e pós-abolição enfatizaram, assim como fizeram acreditar que homens e mulheres negras fossem seres secundários, sem nenhuma habilidade intelectual, e todos os seus direitos como ser social eram inexistentes. Os discursos realizados no período de escravidão afetaram profundamente as mulheres, principalmente, as mulheres negras, que ainda hoje sofrem com o machismo e o racismo ao mesmo tempo. Em consonância com Nascimento (2016, p. 73), "O preço dessa herança foi pago pela mulher negra, não só durante a escravidão, ainda nos dias de hoje".

Além da questão racial, na atualidade ainda se apresenta traços machistas, que têm como ancestral principal, a estrutura patriarcal familiar, sistema que o Brasil herdou de Portugal, onde o domínio do poder é predominantemente masculino. Ao longo do tempo, esse conceito foi estabelecido na população, originando padrão e ideologias em relação às mulheres, acarretando um processo de desigualdade social, em que as mulheres tiveram uma grande perda na escolaridade e empregabilidade. Com as lutas feministas, a desigualdades entre homens e mulheres começaram a ser alteradas. No final do século XIX, os movimentos feministas iniciaram uma transformação social, na qual os direitos das mulheres foram reivindicados. Todavia, mesmo com todas as conquistas que as mulheres tiveram até o atual momento, ainda existe a presente do machismo na sociedade, que muitas vezes está disfarçado, salientando também que há interseccionalidades, e as mulheres negras continuam sendo as mais afetadas (VIGANO; LAFFIN, 2019). 
Assim, dentro dessa complexidade social, a educação é fundamental. Segundo o Sociólogo Durkheim (1975), ela é um processo de socialização, com intuito de integrar os indivíduos no contexto social, por isso está em constante mudança.

Nesta mesma ideia, Tragterber (2018) salienta que a educação é moldada conforme as necessidades da população. Atualmente, a sociedade utiliza-se da educação para a integração dos seres humanos em todas as áreas do meio social, mas no passado, com o progresso do capitalismo, a alfabetização se fez necessária somente para atender às necessidades das questões trabalhistas. A educação sempre se fez necessária na sociedade, mesmo com objetivos diferentes, pois, além de agregar ao ser humano conhecimentos necessários, gera uma maior capacidade de autonomia.

Com o avanço da sociedade e da educação foi possível um grande crescimento e investimento na área da pesquisa científica, gerando um grande benefício para toda a sociedade, em todos os contextos sociais, principalmente na área da saúde, tecnologia e meio ambiente, houve uma grande melhoria na qualidade global dos indivíduos. O crescimento de um país está interligado com a educação e com as suas pesquisas científicas.

Os avanços na educação estão relacionados, em especial, com o processo de ensino e aprendizagem, com destaque para as ferramentas metodológicas. De acordo com Alves e Leite (2018), o professor pode e deve utilizar vários recursos pedagógicos, com isso facilitará o processo de aprendizagem dos seus alunos. Existem inúmeros apoios pedagógicos que o docente pode usar em suas aulas, como: livros didáticos; vídeos; áudios; imagens; textos e outros. O mais utilizado no ambiente escolar é o livro didático, ferramenta usada pelos professores e alunos, sendo considerado um material que está à disposição da comunidade escolar, por isso exerce um papel relevante na aprendizagem. O livro didático tem um papel importante, pois auxilia os professores na organização de suas aulas e durante a aplicação destas, porém deve ser usado de forma crítica e consciente, mesclando em suas aulas com outros recursos (ALVES; LEITE, 2019).

Colaborando com essa ideia, Silva, Alves e Giannotti (2006) salientam que o livro didático é um material pedagógico importante para os professores e alunos, entretanto não deve ser o único utilizado para obtenção de conhecimento. O livro didático é um recurso que ocupa um lugar considerável no ambiente escolar, diante disso, faz-se necessário que eles sejam atualizados e adaptados conforme as novas diretrizes no Ensino Fundamental e Médio, com métodos e metodologias que façam que os alunos possam ser estimulados a tornarem-se seres pensantes, e não apenas reprodutores de informações. Por isso, é essencial fazer a escolha dos livros didáticos com muita criticidade e por pessoas vinculadas à educação.

Os livros didáticos, sobretudo o de ciências e biologia, têm o papel de trazer para a realidade do aluno a ciência. Desmistificando, consolidando e colaborando com a construção de conhecimentos sólidos a respeito dela. Está presente no cotidiano da sociedade a tecnologia, que foi alcançada pela ciência, sendo assim, é necessário democratizar esse conhecimento para que os cidadãos possam ser inseridos na cultura científica (SILVA; FERREIRA; VIEIRA, 2017).

Ainda, segundo Silva, Ferreira e Vieira (2017), a aprendizagem tem como finalidade proporcionar ao educando uma compreensão de mundo, possibilitando ao sujeito, conhecimentos para realizar escolhas sensatas e coerentes, assegurando-Ihe consciência em relação às suas condutas e atitudes. Diante disso, a escola tem um papel muito importante no contexto social, pois tem como responsabilidade a divulgação científica. 
A importância do ensino científico na formação de cidadãos críticos, reflexivos e conscientes de sua condição de mundo no desenvolvimento do país, tendo em vista que no mundo pós-moderno, em franco desenvolvimento tecnológico, a educação científica é ferramenta determinante na pujança econômica e social de países. (SILVA; FERREIRA; VIEIRA, 2017, p. 37).

Por isso, faz-se necessário o ensino de Ciências e Biologia, o qual teve início a partir da década de 1970, quando o mundo estava passando por grandes mudanças devidos aos problemas relacionados à tecnologia, que tinha como intuito fazer a relação entre ciências, tecnologia e sociedade, movimento que ficou conhecido como CTS, e tinha a finalidade de formar cidadãos críticos, capazes de viver em uma sociedade de uma forma democrática e sustentável (SILVA; FERREIRA; VIEIRA, 2017).

O ensino de Ciências e Biologia é um mecanismo fundamental para a implantação do método científico na sociedade, sendo o professor, mediador desse conhecimento. Com o ensino da ciência o aluno conseguirá entender o mundo e seres que nele habita, e com esta compreensão pode se tornar um indivíduo pensante e crítico diante da realidade. Entretanto, há inúmeros desafios na educação científica, como a carência estrutural, défice na falta de laboratório e equipamentos tecnológicos, professor sem uma educação continuada e a ausência de investimento na educação científica por parte do governo (SILVA; FERREIRA; VIEIRA, 2017).

A história da Ciência muitas vezes passa despercebida ou é esquecida nos livros didáticos. Em especial, no tangente à mulher negra, os relatos dentro desse material parecem ser algo inexistente. Em oposição, surge a Lei de Diretrizes e Bases da Educação Brasileira, apontando a questão étnico-racial como fundamental na educação básica. Como resolver esse impasse? Será que é possível através da história da ciência resgatar a importância das mulheres negras dentro do ensino de Ciências e Biologia?

Desse modo, o uso da história da Ciência como instrumento metodológico no ensino de Ciências e Biologia, poderia minimizar esse contexto de apagamento da memória histórica de mulheres negras na Ciência. O presente trabalho, portanto, objetivou investigar a presença de mulheres negras na história da Ciência, por meio da análise de duas coleções de livros didáticos de Ciência e Biologia, com a finalidade de instrumentalização para o ensino na educação básica, ainda, apresenta-se uma relação de cientistas negras nas mais diferentes áreas das Ciências Biológicas.

\section{METODOLOGIA}

A presente pesquisa é de natureza aplicada, com abordagens quantitativa e qualitativa, com procedimentos técnicos bibliográfico e documental (MINAYO, 2011).

Assim, foi analisada uma coleção de livros de Ciências do Ensino Fundamental e outra de Biologia do Ensino Médio. Para tanto, o critério de escolha das coleções foi que estas deveriam estar presente no último Programa Nacional do Livro Didático (PNLD) para o quadriênio, do livro de Ciências (2020 a 2023) e o de Biologia (2015 a 2017); ambas as coleções, escolhidas pelos professores da rede estadual no município de Cruzeiro do Oeste, região noroeste do estado do Paraná.

Após a escolha das coleções, realizou-se a análise por esgotamento, folheando página por página dos livros, buscando referências (textuais ou visuais) de figuras de mulher negra em cada capítulo. Posteriormente, a fim de colaborar com a instrumentalização de professores de Ciências e Biologia, realizou-se ainda um levantamento dentro da literatura histórica e científica para encontrar mulheres negras presentes nas grandes áreas das referidas disciplinas, usando como referência a classificação 
do CNPQ (Conselho Nacional de Desenvolvimento Científico e Tecnológico). As áreas foram: Genética, Botânica, Zoologia, Ecologia, Morfologia, Fisiologia, Bioquímica, Microbiologia e Parasitologia.

\section{RESULTADOS E DISCUSSÃO}

A primeira coleção analisada foi dos livros de Ciências do Fundamental II, selecionado no último Programa Nacional do Livro Didático (PNLD), referentes aos anos de 2020 a 2023, da coleção "Arariba", que tem como responsável pela obra, Maíra Rosa Carnevalle, é desenvolvido e reproduzido pela editora Moderna. Nos livros do $6^{\circ}$ ao $9^{\circ}$ não foram encontrados nenhuma representatividade de mulheres negras na Ciência, ou seja, há inexistência de conteúdo ou imagem. Nos livros didáticos do $6^{\circ}$ e $9^{\circ}$ encontrou-se um pequeno número de representatividade de mulheres brancas da Ciência, também foi encontrado conteúdos sobre a importância das mulheres no mundo científico, nos livros do $6^{\circ}, 7^{\circ}$ e $9^{\circ}$ ano; e todos os livros tinham figuras aleatórias de mulheres negras.

A Segunda coleção analisada refere-se a do Ensino Médio, selecionada no último Programa Nacional de Livro Didático (PNLD), relativo aos anos de 2015 a 2017. Os livros do $1^{\circ}$ e $2^{\circ}$ ano são da coleção "Ser Protagonista", e tem como autora, Tereza Costa Osorio, é desenvolvido pela editora SM. Já o livro do $3^{\circ}$ ano pertence a marca "Hoje", tendo como escritores, Sérgio Linhares e Fernando Gewandsznajder, desenvolvida e reproduzida pela editora Ática. Nos livros dessas coleções não foi encontrada nenhuma representatividade de mulheres negras da Ciência, tampouco tinham conteúdos referentes às mulheres, apenas foram encontradas imagens aleatórias de mulheres negras.

As mulheres, por meio de suas lutas, conquistaram muitos direitos, como votar, leis que as protege contra qualquer tipo de violência, alcançaram espaços trabalhistas, mas ainda sofrem diversas opressões em seu dia a dia. O machismo está enraizado no inconsciente dos seres humanos, o que faz com esse sistema continue fortemente em sociedade, sendo propagado, sutilmente, pela mídia, Ciência e pelas imagens, esse cenário se torna ainda mais agravante para as mulheres negras (WASCHINEWSKI; RABELO; ALVES, 2017; CARDOSO, 2018).

A invisibilidade das mulheres negras da Ciência fica evidenciada nos livros didáticos do Fundamental II e do Ensino Médio. Esse silenciamento textual e visual ocorre desde a escravização, período em que negros eram tratados como mercadorias, vistos como mero objetos, como se não pertencessem a mesma espécie dos brancos. As mulheres escravizadas, por sua vez, foram sujeitadas a vários tipos de opressões e violência, mesmo após a abolição da escravatura, continuam visualizadas como objetos sexuais pelos homens brancos. Atualmente, ainda existe preconceito e racismo, e as mulheres negras precisam lutar duplamente contra o racismo e o sexismo que está presente em nossa sociedade (WERNECK, 2010; WASCHINEWSKI; RABELO; ALVES, 2017).

Nesse contexto, a mulher negra é vista até hoje com o mesmo olhar, ou seja, sua imagem é sempre colocada com inferioridade e/ou como objeto sexual, isso ocorre em todos os meios de comunicação e, inclusive, nos livros didáticos. Todas as mulheres sofrem dentro patriarcado, mas se a mulher branca encontra dificuldade de ser visualizada e representada na Ciência, para a mulher negra é ainda maior a sua luta. Assim, buscando a resistência a essas ideias, é preciso entender a escola como um espaço social de luta, esclarecimento, onde é realizada trocas de conhecimentos, desconstrução e construção de novos pensamentos, para a formação de um indivíduo sem preconceitos, sexismo ou racismo. 
O livro didático é o material de aprendizagem mais utilizados no meio escolar, no entanto, muitas vezes são elaborados sem criticidade, inferiorizando ou ocultando a presença de mulheres negras, retirando a importância destas no mundo científico. As mulheres negras cientistas precisam ser representadas nos livros didáticos de Ciência, para que os jovens leitores consigam refletir e desconstruir todo o machismo e racismo histórico (MATOS, 2008; BARROZO, 2017).

Por fim, buscando colaborar com a instrumentalização de professores de Ciências e Biologia, realizouse um levantamento dentro da literatura histórica e científica, com o intuito de encontrar mulheres negras presentes nas grandes áreas das Ciências Biológicas. Para tanto, usou-se como referência a classificação do CNPQ (Conselho Nacional de Desenvolvimento Científico e Tecnológico). As áreas foram: Genética, Botânica, Zoologia, Ecologia, Morfologia, Fisiologia, Bioquímica, Microbiologia e Parasitologia.

As informações desse levantamento estão organizadas e apresentadas na tabela 01 .

Tabela 01- Relação de mulheres negras presentes nas diferentes áreas da biologia

\begin{tabular}{|c|c|c|}
\hline MULHERES & IMPORTÂNCIA & ÁREA \\
\hline $\begin{array}{l}\text { - Jaqueline Gees de Jesus; } \\
\text { - Kizzekia Corbett; }\end{array}$ & $\begin{array}{l}\text { - Sequenciou o genoma do vírus } \\
\text { SarCov2; } \\
\text { - Desenvolvimento da primeira vacina do } \\
\text { SarsCov2; }\end{array}$ & Genética \\
\hline - Margaret James Strickland Collins. & $\begin{array}{l}\text { - Pesquisadora sobre cupins, descobriu } \\
\text { uma nova espécie. }\end{array}$ & Zoologia \\
\hline $\begin{array}{l}\text { - Wangari Maathai; } \\
\text { - Viviane dos Santos Barbosa. }\end{array}$ & $\begin{array}{l}\text { Ambientalista, lutava a favor do meio } \\
\text { ambiente; } \\
\text { Desenvolveu um produto catalisador } \\
\text { que reduz emissão de gases poluentes. }\end{array}$ & Ecologia \\
\hline - Jane Wright & $\begin{array}{l}\text { - Foi pioneira no tratamento contra o } \\
\text { câncer. }\end{array}$ & Morfologia \\
\hline - Marie M. Daly & $\begin{array}{l}\text { Estudou os efeitos causados no coração } \\
\text { e nas artérias, por fatores } \\
\text { como :envelhecimento, tabagismo, } \\
\text { hipertensão e colesterol. }\end{array}$ & Fisiologia \\
\hline $\begin{array}{ll}\text { - } & \text { Alice Ball; } \\
\text { - } & \text { Helena Carla Castro. }\end{array}$ & $\begin{array}{l}\text { Desenvolveu um tratamento eficaz para } \\
\text { a Lepra (antes do descobrimento do } \\
\text { antibiótico); } \\
\text { Tratamento de doenças, como a Aids, } \\
\text { desenvolvimento de medicamento para } \\
\text { bactéria resistente. }\end{array}$ & Bioquímica \\
\hline $\begin{array}{l}\text { - Jaqueline Gees de Jesus; } \\
\text { - Kizzekia Corbett; } \\
\text { - Jessie Isabelle Price } \\
\text { - Helena Carla Castro. }\end{array}$ & $\begin{array}{l}\text { - Descobriu o genoma do SarsCov2; } \\
\text { - Desenvolvimento da primeira vacina } \\
\text { contra o vírus SarsCov2; } \\
\text { - Desenvolveu vacinas para proteger } \\
\text { animais; } \\
\text { - Tratamento de doenças, como a Aids, } \\
\text { desenvolvimento de medicamentos } \\
\text { para bactéria resistente. }\end{array}$ & Microbiologia \\
\hline
\end{tabular}


Fonte: Autores, 2021.

Durante muito tempo as mulheres negras não puderam fazer parte da construção do conhecimento científico e filosófico, apesar de a Ciência contemporânea continuar sendo predominantemente masculina, nas últimas décadas o número de mulheres negras cientistas vem aumentado. Porém, estas mulheres continuam na invisibilidade, em decorrência, principalmente, de uma ideologia machista e racista que prevalece, em que persiste o mesmo olhar sobre as mulheres negras construído no período da escravidão (COSTA, 2006; MATOS, 2008).

O levantamento apresentado na tabela 01 sugere que a presença das mulheres negras na Ciência, ou melhor, o reconhecimento de sua importância ainda está longe de ser o ideal. Porém, a popularização da Ciência e a divulgação científica poderia ser um instrumento para contribuir com o aumento da visibilidade delas. Esse fato fica evidente pela baixa quantidade de mulheres encontradas para compor a tabela de sugestões e, ainda, pela ausência de uma referência na área da Botânica.

Nesse sentido, espera-se que as informações presentes na tabela 01 possam colaborar com a prática docente reflexiva e desconstrutiva no ensino de Ciências e Biologia. Que seja um instrumento de visibilidade da mulher negra no espaço escolar, quer seja através de um plano de ensino, planos de aula, sugestões de leituras, ou de qualquer outra forma que o professor julgar apropriado.

Portanto, a educação se torna uma ferramenta essencial para desconstrução do racismo e machismo. É evidente a importância da utilização da representatividade de mulheres negras da Ciência em livros didáticos, material pedagógico que possibilita conhecer as contribuições que elas trouxeram para as áreas das Ciências, além disso, ao abordar assuntos relacionados às mulheres negras, ressaltando a sua importância e seu papel dentro da sociedade, possibilita-se reconstruir um novo olhar sobre estas mulheres (COSTA, 2006; MATOS, 2008).

\section{CONSIDERAÇÕES FINAIS}

Os resultados apresentados na presente pesquisa, mesmo que representado em um pequeno recorte, demonstram a perpetuação da invisibilidade das mulheres negras dentro da Ciência. Ausência essa que tem sua origem histórica e alimenta a perpetuação do sexismo e do racismo.

Dessa forma, faz-se necessário promover um movimento de resistência contra esse discurso falado e não falado de manutenção da invisibilidade feminina negra nas escolas, e fortalecer a representatividade de mulheres negras nos livros didáticos, pois com o estudo sobre estas mulheres é possível iniciar um processo de desconstrução desses sistemas, reconstruindo um novo pensamento em relação a elas dentro do mundo científico e, ainda, contribuir com o empoderamento de novas mulheres para este ramo de trabalho, em especial as jovens.

\section{REFERÊNCIAS}

ALVES, F. C. S.; LEITE, M. J. S. A história e cultura afro-brasileira nos livros didáticos de arte e língua portuguesa/ literatura. Educação em Debate, Fortaleza, n. 76, p. 40. Maio/ago. 2018. Disponível 
em http://www.repositorio.ufc.br/bitstream/riufc/38480/3/2018_art_fcsalvesmjsleite.pdf. Acesso 26 de mar.2020.

BARRAZO, M. B. A invisibilidade das mulheres negras e o branqueamento do território nos livros didáticos de geografia sob a ótica da lei 10.639/03. Encrespando, Rio de Janeiro, v. 1, n. 1, jul. 2017. Disponível em: https://encrespando.jur.puc-rio.br/index.php/files/article/view/8/8. Acesso em 23 de nov. 2020.

CARDOSO, C. P. Experiências de mulheres negras e o feminismo negro no Brasil. Revista da ABPN, Bahia, v. 10, n. 25, p. 217-328, mar./jun. 2018. Disponível em:[http://www.scielo.br/pdf/ref/v26n1/1806-9584-ref-26-01-e51328.pdf]. Acesso em 23 de mar. 2020.

CARNEVALLE, M. R. Ciências (Ensino Fundamental I). Arariba mais. $1^{\circ}$ Edição. São Paulo: Moderna, 2018.

COSTA, M. C. Ainda somos poucas. Exclusão e invisibilidade na ciência. Cad. Pagu, Campinas, n. 27, jul/dez. 2006. Disponível em: https://www.scielo.br/scielo.php?script=sci_arttext\&pid=S0104$83332006000200018 \&$ lng=pt\&tIng=pt. Aceso em 25 de nov. 2020.

CUNHA, M. F. Casamentos mistos: entre a escravidão e liberdade Franca-São Paulo/ Brasil, Século XIX. Rev.Bras. Estud. Populb, São Paulo, v. 34, n. 02, p.223-242, maio. 2017. Disponível em: http://www.scielo.br/pdf/rbepop/v34n2/0102-3098-rbepop-34-02-00223.pdf. Acesso em 19 mar. 2020.

DURKHEIM, É. Educação e Sociologia. São Paulo: Edições Melhoramentos, 1975.

IBGE - INSTITUTO BRASILEIRO DE GEOGRAFIA E ESTATÍSTICA. População chega 205,5 milhões, com menos brancos e mais pardos e pretos. Brasil: IBGE, 2019. Disponível em: https://agenciadenoticias.ibge.gov.br/agencia-noticias/2012-agencia-de-noticias/noticias/18282populacao-chega-a-205-5-milhoes-com-menos-brancos-e-mais-pardos-e-pretos. Acesso em 18 de Mar. 2020.

LINHARES, S.; GEWANDSZNAJDER, F. Biologia hoje. 2 ed. Ática, 2013.

MATOS, M. Teorias de gênero ou teorias e gênero? Se e como os estudos de gênero e feministas se transformaram em um campo novo para as ciências. Estudos Feministas, Florianópolis, v. 16, n. 2, p. 440, maio/ago. 2008. Disponível em: https://www.scielo.br/pdf/ref/v16n2/03.pdf. Acesso em 19 nov. 2020.

MINAYO, M. C. S.; DESLANDES, S. F.; GOMES, R. Pesquisa social: teoria, método e criatividade. 30 ed. Petrópolis: Vozes, 2011.

NASCIMENTO, A. O genocídio do negro brasileiro: processo de um racismo mascarado. 3 ed. São Paulo: Perspectivas, 2016.

OSORIO, T. C. Biologia - $1^{\circ}$ ano: ensino Médio. Ser protagonista. 2 ed. São Paulo: Edições SM, 2015.

SILVA, A. F.; FERREIRA, H. C.; VIERA, C. A. O ensino de ciências no fundamental e médio: reflexões e perspectivas sobre a educação transformadora. Exitus, Santarém, v. 7, n. 2, p. 283-304, maio/ago. 2017. Disponível em:

http://www.ufopa.edu.br/portaldeperiodicos/index.php/revistaexitus/article/view/314/262. Acesso em 01 abr. de 2020. 
SILVA, E. R. L.; ALVES, L. F. A.; GIANNOTTI, S. M. Análise do conteúdo de artrópodes em livros didáticos de biologia do ensino médio e o perfil do professor: estudo de caso. Varia Scientia, Cascavel. v. 6, n. 11, p. 83-98, ago. 2006. Disponível em: http://e-

revista.unioeste.br/index.php/variascientia/article/viewArticle/709. Acesso 26 mar. de 2020.

TRAGTERBER, M. A escola como organização complexa. Educ Soc, Campinas, v. 29, n. 142, p. 188202, Jan./mar. 2018. Disponível em: http://www.scielo.br/pdf/es/v39n142/1678-4626-es-39-142-

183.pdf. Acesso em 25 mar. de 2020.

VIGANO, S. M. M.; LAFFIN, S. M. M. Mulheres, políticas e públicas e combate à violência de gênero. Dossiê, São Paulo, v. 38, 2019. Disponível em:

http://www.scielo.br/scielo.php?script=sci_arttext\&pid=S0101-90742019000100311. Acesso em 23 mar. de 2020.

WASCHINEWKI, S. C.; RABELO, G.; ALVES, I. G. Gênero e a invisibilidade da mulher nos livros didáticos de geografia do ensino médio no sul de Santa Catarina. Inter-Ação, Goiânia, v. 42, n. 3, p. 572-589, set./dez. 2017. Disponível em: file://C:/Users/Usuario/Downloads/48855Texto\%20do\%20artigo-222507-1-10-20180605\%20(3).pdf. Acesso em 17 nov. de 2020.

WERNECK, J. Nossos passos vêm de longe! Movimentos de mulheres negras e estratégias políticas contra o sexismo e o racismo. Revista da Associação Brasileira de Pesquisadores/as Negros/as (ABPN), v. 1, n. 1, p. 07-17, jun. 2010. Disponível em:

file://C:/Users/Usuario/Downloads/iheid-6316\%20(1).pdf. Acesso em 17 nov. de 2020.

Submissão: 21/01/2021

Aceito: 22/03/2021 